\title{
New Editor-in-Chief, J. Solid State Electrochemistry
}

\author{
Yair Ein-Eli ${ }^{1}$
}

Published online: 9 February 2022

(c) The Author(s), under exclusive licence to Springer-Verlag GmbH Germany, part of Springer Nature 2022

\section{The Publisher of the Journal of Solid State Electrochemistry would like to welcome Yair Ein-Eli as the new Editor-in-Chief}

Yair is a Professor in the Department of Materials Science and Engineering (MSE) at the Technion - Israel Institute of Technology (Haifa, Israel). He completed his BSc studies in 1990 at the Chemistry Department, Bar-ilan University (Ramat-Gan, Israel) and graduated (PhD) from Bar-Ilan University in 1995. He joined (2001) the Technion's MSE Faculty after serving 3 years as the VP of R\&D of Electric Fuel Ltd. (Bet-Shemesh, Israel). Before that (1995-1998), he was a post-doctoral fellow at Covalent Assoc. Inc. (Woburn, MA, USA). Yair served as MSE's Dean for 4 years, between 2018 and 2021.

Current projects and interest of Yair involve basic and applied electrochemistry research in the field of power sources, involving advanced materials for Li-ion batteries, alkaline batteries, metal-air and fuel cells. He is also engaged in research and development of electroplating methods, as well as corrosion inhibitor studies. Yair has published close to 200 publications in these topics. In December 2015, he was appointed as the Topical Editor in the Journal of Solid State Electrochemistry, handling manuscripts dealing with Li-ion batteries, supercapacitors and fuel cells, and in October 2021, he was appointed as a Deputy to the Editor-in-Chief, Prof. Dr. Fritz Scholz, the Founding father of the Journal.

\section{A short message from Yair}

It is indeed a strange time...The retirement of Prof. Dr. Scholz from the Editorial office after more than 25 years of leading the Journal, along the abnormal and unthinkable events that have troubled our world since COVID-19

Yair Ein-Eli

eineli@technion.ac.il

1 Department of Materials Science and Engineering, Technion - Israel Institute of Technology, 3200003 Haifa, Israel emerged into our normal daily life 2 years ago, indicates that the current time is indeed eccentric. I am writing this message to the loyal readers of the Journal (while we learn that Omicron mutation of COVID is globally spreading in a rapid and most alarming fashion) with a great hope that science and technology will continue to provide us the support and assistance, as many a time proven during the mankind history.

Technology and science are proven again as the best and only way to battle pandemic, keeping and advancing our lives. Along the vast effort to keep us safe and healthy, scientists continue working in their labs to improve our quality of life. In our arena, electrochemistry is proven to be a central technology that continues to progress, flourish and evolve, establishing the foundations for living in a unique era.

I would like to thank Fritz, the founder father of the Journal, who had dedicated more than 25 years of academic service and research to position the Journal as one of the leading journals in solid state electrochemistry and electrochemistry in general. Fritz's passion and enthusiasm towards science and education serve as a model for all of us.

We are also saying goodbye and farewell to Prof. György Inzelt and Prof. Su-Il Pyun, who retired from the Journal's editorial board, serving as Topical Editors for polymer-modified electrodes and polyelectrolytes and metal deposition and corrosion, respectively. The current team of Editors is composed of experienced professionals, serving as Editors for many years already. This excellent group of people is a powerful one, being expert in their fields, highly motivated and eager to keep the highest standard in processing the valuable scientific output, to you, our loyal readers.

Allow me please to outline my plans, expectations and vision for the Journal: The Journal will continue to keep its high standards, publishing manuscripts that only report on significant advance that is likely to be of broad interest in solid state electrochemistry. The Journal's primary objective is the publication of forefront fundamental and applied research in the electrochemical science and technology and as such, this will continue to be the Journal's motif. We will make efforts to reduce the overall time consumed for 
the evaluation of the manuscript quality, as well as for the time to bring the accepted article into print. Our publisher, Springer-Nature, continuously supports the Journal authors with an extensive Copy-Editing (contrary to other large Publishers), or with the possibility to publish coloured Figures free of charge - just to name these two amongst many. At the same time, we are encouraging the authors to carefully read and revise their manuscripts for their technical English level, before submitting them to the Journal. Great ideas and excellent work should be clearly and well written, otherwise they may be lost due to a rejection by reason of poor language.

We are obligated to strengthen our ties with the Electrochemistry community, especially and more vigorously, in the COVID - and post-COVID - era. For that, we will publish special volumes on selected Conferences, and special Topical Issues, together with Festschrift Volumes for renowned experts in our field. Let me shortly present three selected examples of the forthcoming months to you:

We are happy and honoured to announce a special issue, celebrating Prof. Doron Aurbach's 70th birthday (Festschrift Volume) for this autumn 2022. Doron is a world leading electrochemist, and his work includes all aspects of nonaqueous electrochemistry, implicating the development of advanced batteries and supercapacitors. His "hall of fame" and world recognition is the invention of the rechargeable $\mathrm{Mg}$-batteries. Doron was among the first researchers who implemented in operando and in situ analysis, combining imaging, spectroscopic analysis and microscopic tools to better understand the electrochemical processes and surface reactions occurring during the electrochemical processes of metals and electrodes. His work promoted and implemented important basic scientific principles, enabling a practical development of high energy density power sources.

A second special issue that will be published towards the end of 2022 will be dedicated to "Triple E - Electrochemistry in Eastern Europe". In the twentieth century, Eastern Europe researchers generated and disseminated an enormous amount of electrochemical knowledge. Schools and institutes operated in EE countries having highly committed researchers and their great advancements in the 1930s-1990s gave birth to several generations of electrochemists working all around the globe. Triple- $E$ special issue is planned to demonstrate the outcome of this development, as well as the perspectives. The goal of Triple- $E$ special issue is to present the progress of the national electrochemical schools in EE countries, the evolution of their predominating topical areas and the links to their historical roots. The issue will combine invited Reviews and Feature Articles, as well as original research articles.

A third special topical issue with the tentative title "Electrochemistry in Emerging Human Health" is planned for early 2023, and it will examine and focus on the wide aspects of electrochemistry in human health. The topics that will be covered in this special issue include electrophysiology, electrochemistry of biological fluids, cell electrochemistry, electrochemical detection and treatment of tumours, electrochemical diagnostics, biomedical sensors and more.

I would like to conclude my thoughts by providing my vision to the Journal of being "better, stronger, faster and higher". Each one of us can relate to these 4 ambitious targets, and I am certain that together, we will strive to achieve them on behalf of the Journal.

Wishing all of us a good health and prosperous research activities.

Yours,

Yair

Publisher's Note Springer Nature remains neutral with regard to jurisdictional claims in published maps and institutional affiliations. 